\title{
LEAN AND COMPLEX SYSTEMS: A CASE STUDY OF MATERIALS HANDLING AT AN ON-LAND WAREHOUSE FACILITY SUPPORTING SUBSEA GAS OPERATIONS
}

\author{
PER ENGELSETH \& DANIELA GUNDERSEN \\ Department of Logistics, Molde University College, Norway.
}

\begin{abstract}
Commonly warehouse management is subject to deterministic planning procedures within the organizational scope of supply chain management. Lately lean principles have become more widespread and also adapted to develop materials handling within warehouses. Several facets of analysis are considered in this case study on outsourced warehousing in the Norwegian petroleum industry. This study reveals empirically how outsourced warehousing as service provision involves an organization problem with waste found both at the service management and at the process levels. Analysis points to how lean principles of process improvement may be combined with complex systems thinking. The case reveals examples of how warehouse management and its operations are full of complexities leading to waste. While lean usually is used hands on to manage these wastes through manual incremental development, another organisation of continuous innovation is suggested here. Lean is suggested be developed as organizational context of complex systems information warehouse management system software. Following lean principles evokes many types of process waste at the studied warehouse. Instead on following the manual stepwise and continuous process improvement approach of lean in all areas of organization, a more radical change to complex systems evident in information system design to support warehousing processes is proposed with lean as its organizational context.
\end{abstract}

Keywords: case study, complex systems, lean, material handling, Norwegian petroleum industry, services industry, Warehouse management.

\section{LEAN AND ITS COMPLEXITY}

This paper juxtaposes the concepts of "Lean" and "Complex Systems" in the context of supply chain management (SCM) as principles of production. To juxtapose concepts means a search for contrasting effects through interrelating these words in a text. Meanings may thus be developed as a conceptual exercise. These are two concepts, "Lean" and "Complex Systems" when used within SCM are thus considered associated in with different approaches on how to manage flows of people, goods and information. Herein lies the academic value of this exercise.

The key to efficient SCM is associated with, following the seminal works of Forrester [1], the integration of differentiated and sequentially interdependent actors in the supply chain to avoid production inefficiencies through e.g. bullwhip-like effects. Information distortion is a key challenge in SCM and collaboration is deemed the main remedy to this to secure logistics quality in the form of handing down to the end-user in the supply chain service meeting customer expectations regarding the time, place and form characteristics [2]. In relation to aims of creating a true "value chain" out of just any other "supply chain", the notion customer perceptions need to be significantly elevated. These notions are all-important when considering Lean and Complex Systems in a SCM context. This sets forth our understanding of what constitutes "Lean" and how lean is associated with "complex systems" thinking. Juxtaposing these two concepts implies also respecting their integrity as different, not forcing them to merge into some new concept. This implies accordingly that this paper seeks ways to use 


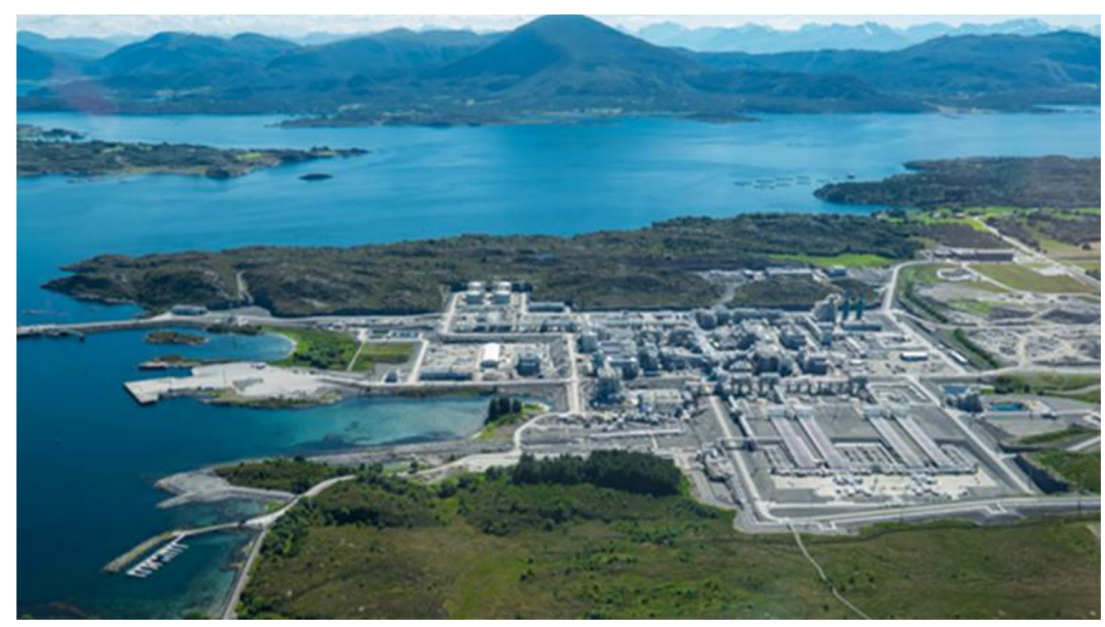

Figure 1: The Nyhamna facility

these concepts to improve materials handling at a same time, but keep the concepts unchanged. The following text provides introductions to "lean thinking" and "complex systems" and "services" as basis for discussion about the empirical findings in section six.

The case concerns warehousing management at the Nyhamna facilty in North-western Norway. The well stream from Ormen Lange, Norway's second largest gas field, is processed at the land facility in Nyhamna since 2007, owned and operated by Shell, where the gas spends just about ten minutes before it is exported $1.200 \mathrm{~km}$. through one of the world's longest subsea pipelines, Langeled, to Easington in England. Shell is now expanding this facility involving suppliers of materials and components from all over the world. Among these suppliers is our focal firm we call Aurora. The analytical framework ids developed through first introducing lean thinking, followed by complex systems and warehousing services.

\section{LEAN THINKING}

Lean management principles evolved from Taylor's scientific management through Ford's principles of mass production, continuing through Ohno's just-in-time manufacturing system found in the Toyota Production System [3], into an increasingly knowledge-based humanistic system for process development setting people in focus as basis for industrial manufacturing process improvement $[4,5]$. The term "lean" is itself a relatively recent invention. It was first coined by John Krafcik in a fall 1988 article, Triumph of the Lean Production System, published in the Sloan Management Review, based on his master's thesis at the MIT Sloan School of Management. The term "lean" amplifies the core objective of the Toyota Production System [3] that is associated with elimination of waste, or muda as it is called in Japanese. One of the key routes to process development through lean thinking is to understand the present based on the past; thereby improve future production. Extensive, and potentially continuous modelling of existent production processes to reduce the mainly time-associated muda lays ground for incremental change. Teamwork is an important enabler of such development, and the role of management is to enable this change; the notion of "servant leadership". Lean is 
accordingly a predominately manual approach to process change and values interaction set in norms to develop production to economise production.

\section{COMPLEX SYSTEMS}

Complexity is defined as "... a property of an open system that consists of a large number of diverse, partially autonomous, richly interconnected components, often called agents, has no centralized control and whose behaviour emerges from the intricate interaction of agents and is therefore uncertain without being random" [6; p. 5]. Rezevski and Skobelev [6] continue by pointing out that the key features of complexity are openness, diversity, partial autonomy and interconnectedness of agents, lack of centralized control and emergence. This interlinking of components entails interdependence. In a complex system management must consider how to manage processes where components are continually in change regarding not only logistics; the time, place and form features, but also how they interact as well as how this interaction is perceived in a value chain. In a complex system, resource objects are not only transformed through production, but their evaluation may change as time unfolds. Complexity entails at core emergence. This is the focus of analysis in complex systems thinking. "Generative emergence" entails change found in organizations and therefore inclined to be managed [7]. A key attribute of process development following complex systems logic is supporting connectivity through information systems designed explicitly to manage generic emergence in processes. There is an inducement when developing supply following complex systems logic towards automating this interaction by designing software that enables navigation as opposed to deterministic planning.

\section{WAREHOUSEING SERVICES}

Service management was initially developed conceptually through the services marketing literature $[8,9]$. Particularities of services supply include that services are intangible, heterogeneous, perishable, and inseparable regarding supplier-customer interaction [10]. Grönroos [8] highlights particularities of service production including that services at some extent services are impalpable. This means that they consist of a sequence of activities rather than objects, that services can be generated and consumed contemporaneously and that the customer often takes part in the service production process. Service processes are therefore inherently complex in nature, possibly more complex than manufacturing processes which represent the empirical foundation for the conceptual development of Lean principles.

In its generic form, services are commonly classified as intangible, heterogenic, inseparable, and perishable. This static classification provides, according to Spring and Araujo [11], limited analytical value since it does not consider interactions involved in services production. This implies that producing services is organized differently than in manufacturing $[12,13]$. People are fundamental to achieving quality in services $[9,10]$. Sampson and Froehle [14] state that: "With service processes, the customer provides significant inputs into the production process". This underpins the importance of interaction and that value in service is inherently to some degree co-created. A service cannot start before the customer informs the supplier with its requirements. This requirement may then also be negotiated.

According to Sampson and Froehle [14], three types of customer inputs can be found in services: (1) the customer person; (2) physical resources such as customer belongings, tools and other tangible objects; and (3) information. These resources are pooled and in combination produce a service. Another distinct feature of service supply is that these supply chains can be characterized having a non-linear "hub and spoke" network-like structure. Sampson 
and Froehle [14] state that seldom more than three tiers of firms are found in a service supply chains; it is in principle a triadic form of collaboration.

A simple way to analyse services from a strategic viewpoint is to apply interdependency theory [15]. According to Thompson's [15] framework, all forms of interdependencies, sequential, pooled and reciprocal, are accountable in all types of supply; it is their importance that varies based on an evaluation if value chain power structure. Complete industries often show similarities regarding their power structure, making it sensible to consider how industrial type particularities impact on interdependencies. Services are characterized by either predominately pooled or reciprocal interdependencies.

Following Thompson [15], Stabell and Fjeldstad [16] propose a framework where services may be classified as value shops where reciprocal interdependencies are dominant, or value networks where pooled interdependencies are dominant. This implies that within services, two main types of interdependencies may be found as power structure. When developing service processes muda (waste) is not predominately found in how operations are timed sequentially (as in the lean principle of "tact time") but how resources are pooled and how actors interact. In services muda is associated with either mainly pooled or reciprocal interdependency. Intensive interaction to mutually adjust production is found in reciprocally interdependent relationships. When pooled interdependencies are predominant, connectivity achieved through production resource standardization (including people to support resource mediation) using mediating technology needs to be developed.

Waste in services concern e.g. random arrivals, inconsistent specification, and varying input quality that influence service processes as capacity, demand management and quality management [14]. Bicheno and Holweg [17] discuss, from a lean perspective, various forms of muda found in services. These are: (1) delay, (2) duplication, (3) unnecessary movement, (4) unclear communication, (5) incorrect inventory, (6) poor customer service, and (7) transaction and production errors. Following lean thinking, these problems should be solved through incremental change that is founded on worker empowerment, so that they notice and are motivated to drive change. From complex systems thinking, change should involve fundamentally changing the system structure, especially its information system, to create a supporting context helping agents navigate through rather than plan themselves away from uncertainty and experienced challenging events emerging as warehousing production unfolds following the timeline as descriptive mode.

\section{METHOD}

Without a research focus it is easy to become overwhelmed by the volume of data in qualitative research [18]. In this case of warehouse management, the studied processes involve details regarding how and why people acts as they do in a warehouse management context. Only an abstract of these findings are presented in the following narrative.

Following Miles and Huberman [19] and Yin [20] the case study research strategy was used because it provided grounds to explore warehouse processes in their real context. Taylor and Fearne [21], Fernie and Thorpe [22] and Holweg and Pil [23] state that case studies is appropriate when describing actors, structure and agency relations taking place through social interaction in further detail. Case studies (1) make it possible to answer "how" and "why" research questions, (2) researchers cannot manipulate the behaviour involved during the research process and (3) researchers can seek a picture of the context the phenomenon is embedded in. 
This is a single case study. This entails that process details witting the case are reported [24], as opposed to comparison between cases. According to Meredith [25] direct observation is more important than second or third observation. This also implies retrospective recollection of events and processes, a limitation and potential bias since things may be perceived wrongly and recollections may be distorted over time. Any researcher who participates in an organization over an extended period of time will find it is difficult not to participate actively in the organization [26]. The main risk of participant observation as a method for collecting data is the danger of "going native" and loses the perspective necessary for a researcher.

One of the researchers, working in the company in question, had therefore ample access to documentation, as well as potential to discuss findings with co-employees, workers as well as management. Cross reference to secure credibility was done through informal interviews with different employees here they describe the situation before September 2016, when they had only 5-6 people working there.

\section{CASE TEXT}

The expansion project is large and Aurora has a central role in the project. More than 160 workers are present on site, divided on different departments, disciplines and locations. Thus is an organization problem. The amount of work is large, the products used are many, the activities are complex. Due to the size, the need for communication and interaction is high and coordination is complicated. Overlapping project activities between engineering, production and warehouse department: Some of the tasks are not clearly defined from the beginning. This creates extra work and waste of time and resources. Maturity of design/ technology, meaning some of the products doesn't fit the gas pipes. This demands more coordination, since a number of adjustments are necessary.

The case narrative focuses on describing operational weaknesses in warehousing processes. The warehouse processes are shown in Fig. 2:

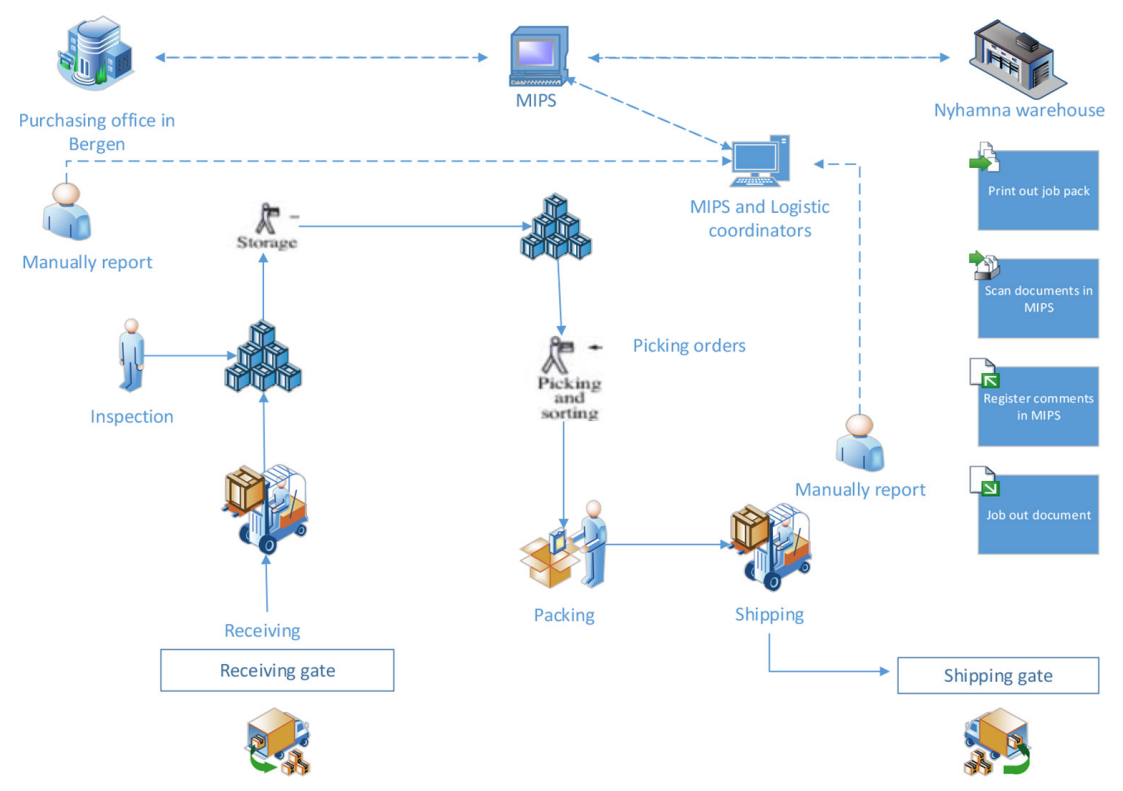

Figure 2: Aurora warehousing process 
Prior making the adjustments, the production staff has to interact with supplier personnel. After the products are modified, the supplier contacts the warehouse. All three departments are in close dialog. Such interactions tend to be very time consuming. The situation can generate delays during the project execution. Collaboration between project partners contributes to the improvement of the services that the warehouse delivers. The communication with the contractor's transport department improved after the warehouse personnel increased and the tasks are better distributed. The same thing happened with other suppliers that handled the transport of new purchased goods. Operational collaboration is a factor that helps coordination and better flow of the project.

Process weaknesses associated with material handling at the Aurora Nyhamna facility are many. After confirming the delivery, the system is not good enough to follow up what happen with the goods. The items are packed, but not delivered. The goods are stored at warehouse and the only way details are registered by manually using the comments in the warehouse management system (MIPS). The workers need to fill out a form whenever they pick up materials. The information on this form is, however, incomplete missing details such as item number, in-warehouse location and volume.

Poor communication is found between foremen, team leaders, General Foremen (GF) and the production department. As an example, the GF asks warehouse to send goods, but the foremen is not informed about the ownership of that job; who is responsible for its operation. Another situation occurs when both Team Leader and GF send same request to warehouse, by making double registration in GF list. Foremen don't use their time to check status on goods. Instead, they prefer to send many e-mails to the warehouse asking for information they could find on their own. Sometimes the foremen forget that they signed and received goods, asking for it again. The attachments in MIPS with signature help the warehouse personnel to prove that goods were sent and received.

Poor handover notes abide from one work-shift to another. Due to the stress and pressure they are faced to, the departments are pointing fingers at each other trying to avoid taking responsibilities for their acts. The production workers don't use enough time to look for goods on site. They prefer that warehouse uses the resources instead.

Several factors that affect performance at the warehouse include integration of engineering, production and warehouse departments. These are located at the same site. Such a level of integration demonstrates an important factor in facilitating coordination. They have direct communication, but sometimes this is challenging because there are too many people involved (workers worked in shifts, changing often without perfect handover notes).

\section{CONCLUSION}

Based on this description some propositions for merging lean thinking with complex systems in the context of warehousing management emerge. Materials handling involves a set of what intuitively should be considered relatively simple processes involving receiving goods, handling them at the warehouse for cross-docking or storage, picking and dispatching them. Lean challenges practitioners to continuously never forget to push for improvement. It is concerned with understanding the root causes of muda.

Lean is the people-focused tough highly manual path to economizing e.g. warehousing management. Applying lean thinking concerns taking small steps at a time meaning following a line of incremental deployment. Within lean thinking error detection involves people perceiving and in personal modes reporting and through teams working on this. Improvement 
rests on the shoulder of the people in a company, both labour and management, including how well these are culturally integrated, share a common organizational discourse.

Neither the studied company, Aurora nor any of their co-creators in the value chain apply complex systems thinking as such. They do follow lean principles to some degree, enough to understand that the status quo of the described warehousing is not satisfactory. Complex systems can provide an alternative structure to improving the process of warehousing as everyday operations. Mainly, this would imply to start with a form of radical change. This is different from lean thinking and its focus on incremental change. Lean is not a radical process improvement strategy. It takes the safe path to organizational development. If one step ahead is wrong, this step can easily be corrected. Investing in complex systems software would, however, be a disruptive radical innovation to the studied warehouse management systems.

Implementing complex systems thinking, however, would demand investing in an information system and production resources where focus would be on system flexibility and interconnectivity. Lean, with its focus on incremental change, also has no prominence for deterministic long-term supply planning. Complexity, defies linear logic as it brings with it self-organization and feedback loops, wherein the effect is its own cause [27]. In a manner Lean thinking therefore implies a manual variation of complex system due to its line of incremental continuous improvement. This complexity is, however, not immediate since it demands human intervention. This may take some time and demands some form of human effort. This may itself be a form of muda, waste associated with process improvement. It is at this organizational layer, surrounding use of complex systems software in warehouses, that lean principles are suggested be applied.

In sum, complementarity is accordingly suggested applied to mix these methodologies for process improvement. Lean is suggested as organizational back-up for more automated warehouse processes applying complex systems methodology. Further research may be dedicated to reporting on such cases of process improvement within a wide range of logistics applications.

\section{REFERENCES}

[1] Forrester, J., Industrial Dynamics. Waltham, MA: Pegasus Communications, 1961.

[2] Alderson, W., Dynamic Marketing Behavior. A Functionalist Theory of Marketing, Homewood IL, Richard D. Irwin, 1965.

[3] Ohno, T., Toyota Production System. Beyond Large Scale Production, Boca Raton FL, CRC Press, 1988.

[4] Womack, J.P., Jones, D.T. \& Roos, D., The Machine That Changed the World: The Story of Lean Production, New York, Rawson Associates, 1990.

[5] Holweg, M., The genealogy of lean production. Journal of Operations Management, 25(2), pp. 420-437, 2007. https://doi.org/10.1016/j.jom.2006.04.001

[6] Rzevski, G. \& Skobelev, P., Managing Complexity, Southampton UK, WIT Press, 2014.

[7] Lichtenstein, B.B., Generative Emergence, Oxford, UK, Oxford University Press, 2014.

[8] Grönroos, C., Service Management and Marketing: Managing the Moments of Truth in Service Competition, Lexington MA, Lexington Books, 1990.

[9] Normann, R., Reframing Business: When the Map Changes the Landscape, West Sussex UK, Johan Wiley \& Sons, 2001. 
[10] Ellram, L, Tate, W. \& Billington, C., Services supply management: the next frontier for improved organizational performance. California Management Review, 49(4), pp. 44-66, 2007. https://doi.org/10.2307/41166405

[11] Spring, M. \& Araujo, L., Service, services and products: rethinking operations strategy. International Journal of Operations \& Production Management, 29(5), pp. 444-467, 2009. https://doi.org/10.1108/01443570910953586

[12] Chase, R. \& Garvin, D., The service factory. Harvard Business Review, 6(4), pp. 61-69, 1989.

[13] Oliva, R. \& Kallenberg, R., Managing the transition from products to services. International Journal of Service Industry Management, 14(2), pp. 160-172, 2003. https://doi.org/10.1108/09564230310474138

[14] Sampson, S.E. \& Froehle, C.M., Foundations and implications of a proposed unified services theory. Production and Operations Management, 15(2), pp. 329-343, 2006. https://doi.org/10.1111/j.1937-5956.2006.tb00248.x

[15] Thompson, J.D., Organizations in Action, New York, NY: McGraw Hill, 1967.

[16] Stabell, C. B. \& Fjeldstad, Ø. D., Configuring value for competitive advantage: on chains, shops, and networks. Strategic Management Journal, 19(5), pp. 413-437, 1998. https://doi.org/10.1002/(sici)1097-0266(199805)19:5<413::aid-smj946>3.3.co;2-3

[17] Bicheno, J. \& Holweg, M., The Lean Toolbox: The Essential Guide to Lean Transformation, Buckingham UK, PICSIE Books, 2009.

[18] Eisenhardt, K.M., Building theories from case study research. The Academy of Management Review, 14(4), pp. 532-550, 1989. https://doi.org/10.5465/amr.1989.4308385

[19] Miles, M.B. \& Huberman, A.N., Qualitative Data Analysis, Thousand Oaks, CA: Sage, 1994.

[20] Yin, R.K., Case Studies Research: Design and Methods, Thousand Oaks, CA: Sage, 2009

[21] Taylor, D. \& Fearne, A., Towards a framework for improvement in the management of agri-food SCs. Supply Chain Management: An International Journal, 11(5), pp. 379$384,2006$. https://doi.org/10.1108/13598540610682381

[22] Fernie, S. \& Thorpe, A., Exploring change in construction: supply chain management. Engineering, Construction and Architectural Management, 14(4), pp. 319-333, 2007. https://doi.org/10.1108/09699980710760649

[23] Holweg, M. \& Pil, F.K., Theoretical perspectives on the coordination of supply chains. Journal of Operations Management, 26(3), pp. 389-406, 2008. https://doi.org/10.1016/j.jom.2007.08.003

[24] Voss, C., Tsikriktsis, N. \& Frohlich, M., Case research in operations management. International Journal of Operations and Production Management, 22(2), pp. 195-219, 2002. https://doi.org/10.1108/01443570210414329

[25] Meredith, J., Building operations management theory through case and field research. Journal of Operations Management, 16(4), pp. 441-454, 1998. https://doi.org/10.1016/s0272-6963(98)00023-0 
P. Engelseth \& D. Gundersen, Int. J. of Design \& Nature and Ecodynamics. Vol. 13, No. 2 (2018) 207

[26] Åhlström, P. \& Karlsson, C., Longitudinal Field Studies, in Researching Operations Management. London: Routledge, 2009.

[27] Jay, J.J., An Introduction to Systems Thinking, The Ecosystem Approach, eds. D. Waltner-Toews, J.J. Kat and N.-M. Lister, Columbia University Press, pp. 3-11, 2008. 